\title{
Prussian Blue-coated interdigitated array electrodes for possible analytical application
}

\author{
M. Hartmann and E.W. Grabner * \\ Institute of Physical and Theoretical Chemistry, University of Frankfurt, Niederurseler Hang, D-6000 Frankfurt am Main 50 (Germany) \\ P. Bergveld \\ Biomedical Engineering Division, Twente University of Technology, NL-7500 AE Enschede (The Netherlands)
}

(Received 23rd May 1990)

\begin{abstract}
Thin films of iron(III) hexacyanoferrate(II) (Prussian Blue) were electrochemically deposited on interdigitated array (IDA) electrodes, yielding systems which can be considered as chemiresistors in sensing alkali metal ion concentrations in an adjacent electrolyte. This is due to the fact that the conductivity of the film being measured by a steady-state current on application of a voltage to the two-fingered electrodes of the IDA depends on both the redox state of the film and the cation concentration in the electrolyte. From the dependence of the steady-state current on the electrode (bias) potential at variable cation concentrations for different alkali metal ions and for mixtures of alkali metal ions, the possibilities of analytical application were elucidated. In addition, by using the methods of staircase coulometry and scanning conductivity, the electron diffusion coefficient $D_{\mathrm{c}}$ was determined as a function of the redox state of Prussian Blue. It is concluded that Prussian Blue-coated IDA electrodes are, in principle, suitable as chemiresistors for the determination of alkali metal ion concentrations with increasing selectivity in the series $\mathrm{Li}<\mathrm{Na}<\mathrm{K}<\mathrm{Rb}<\mathrm{Cs}$.
\end{abstract}

Keywords: Potentiometry; Array electrodes; Alkali metals

The use of microlithographically defined microarray electrodes for the study of electroactive films such as conducting polymers and redox polymers, resulting in transistor-like systems, was pioneered by Wrighton and co-workcrs $[1,2]$. The deposition of an inorganic mixed-valence compound, namely iron(III) hexacyanoferrate(II) [Prussian Blue (PB)], on an interdigitated array (IDA) electrode was achieved for the first time by Murray and coworkers [3-5]. They demonstrated that PB-coated IDA electrodes can be used successfully for the study of electron transport in PB and in its reduced and oxidized states (Prussian White and Berlin Green, respectively) as well as in dry PB. Thus, since the discovery of PB as a chemically modified electrode [6,7], a deeper understanding has been obtained of a material that has attracted much interest from electrochemists because of its electroanalytical [8], electrochromic [9], charge storage [10,11] and membrane [12] properties.

From the work of Murray and co-workers [3-5, 13] and others [14], it is well established that, when a small voltage is applied to the two-fingered electrodes of a PB-coated IDA, a steady-state current flows, driven by concentration gradients of the high-spin Fe(III/II) states within the film. The steady-state current depends on both the redox state of the film, manifested by its bias potential against a reference electrode, and the concentration of alkali metal ions in the electrolyte. Hence this system acts as a chemiresistor, the conductivity of which, at a constant bias potential, 
is a function of cation concentration. In addition, as the insertion of cations on reduction of $\mathrm{PB}$ occurs at different potentials for different alkali metal ions [15], indicating selectivity, the PBcoated IDA electrode should represent a selective alkali metal ion sensor.

In this paper, it is shown that PB-coated IDA electrodes actually are ion-selective chemiresistors. Some theoretical considerations are presented describing the relationship between steady-state current and cation concentration, in addition to experiments confirming this relationship. Further, based on a method for the determination of the electron diffusion coefficient, $D_{\mathrm{e}}$, by "staircase coulometry" combined with "scanning conductivity" [5], $D_{\mathrm{e}}$ values were determined for various cations and at different potentials.

\section{EXPERIMENTAL}

The interdigitated arrays consisted of twofingered electrodes, with 50 fingers each, being deposited on an area of $1 \times 1 \mathrm{~mm}^{2}$ of an insulating substrate. Thus the total width of the fingers was 1 $\mathrm{mm}$, and the sum of the width of each finger, $w$, and the gap between two adjacent fingers, $d$, were $10 \mu \mathrm{m}$ (Fig. 1). The active area of the IDA was determined by an insulating layer of polyimide deposited around the array. In an early stage of the study, the insulating substrate of the IDA was $\mathrm{Ta}_{2} \mathrm{O}_{5}$, and the fingers of height $h=0.7 \mu \mathrm{m}$ were made from $\mathrm{Ti}-\mathrm{Ag}-\mathrm{Au}$; the width $w$ was identical with the gap $d(5 \mu \mathrm{m})$. As the structure suffered from corrosion after deposition of a PB film and exposure to the electrolyte, an improved version of IDA was used with $\mathrm{Pt}$ fingers of height $h=0.3$ $\mu \mathrm{m}$ adhered to a $\mathrm{SiO}_{2}-\mathrm{Si}$ substrate by a $30-\mathrm{nm}$ thick layer of $\mathrm{Ti}$; the dimensions of this type of IDA were $w=7 \mu \mathrm{m}$ and $d=3 \mu \mathrm{m}$. The microstructures were patterned by means of ion beam etching, a technique which is especially suitable for very fine structures with steep profiles [16].

After rinsing the IDA electrodes for several minutes in concentrated $\mathrm{HCl}$ and subsequently washing them with water, PB films were potentiostatically deposited from an aqueous solution of $20 \mathrm{mM} \mathrm{FeCl}_{3}, 20 \mathrm{mM} \mathrm{K}_{3} \mathrm{Fe}(\mathrm{CN})_{6}$ and $0.01 \mathrm{M}$ (a)

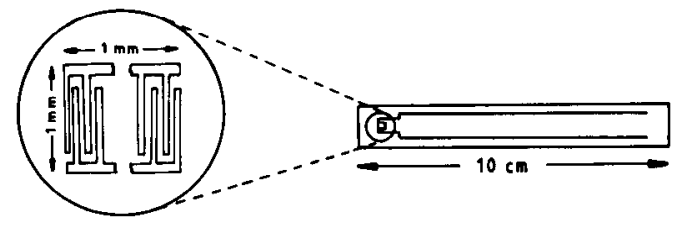

(b)

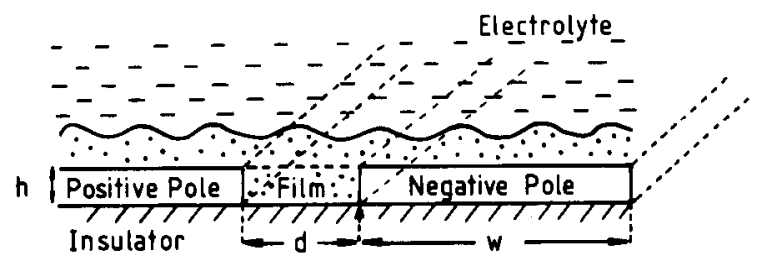

Fig. 1. (a) Geometric arrangement and (b) cross-section of an interdigitated array electrode. $w=$ Width of a finger; $d=$ gap between two fingers; $h=$ height of a finger.

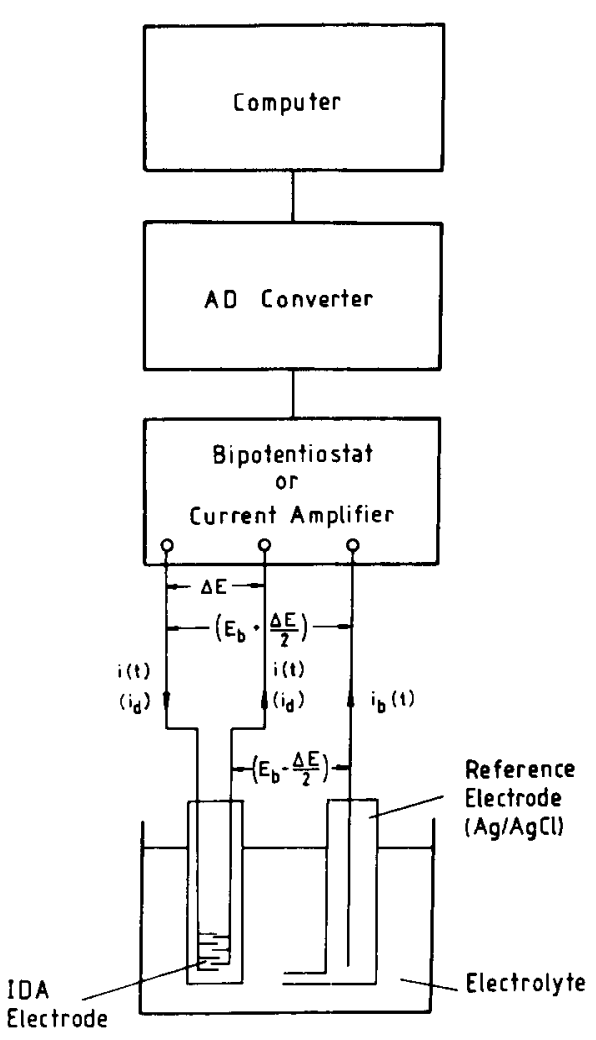

Fig. 2. Arrangement of IDA measurements. $\Delta E=$ voltage between the two-fingered electrodes; $E_{\mathrm{b}}=$ average bias potential; $i(t)=$ current flowing between the fingcred clectrodes; $i_{\mathrm{d}}=$ steady-state current; $i_{\mathrm{b}}(t)=$ bias current. 
$\mathrm{HCl}$ at $0.5 \mathrm{~V}$ vs. $\mathrm{Ag} / \mathrm{AgCl}$ for $2.5 \mathrm{~min}$. This procedure led to a charge density of about $20 \mathrm{mC}$ $\mathrm{cm}^{-2}$, corresponding to an average film thickness of $300 \mathrm{~nm}$ (calculated from a PB elementary cell with a volume of $1 \mathrm{~nm}^{3}$ and containing four redox centres). All chemicals used (Merck, Fluka) were of analytical reagent grade and the water was triply distilled. The solutions were degassed by bubbling argon throughout.

Prior to the experiments with the PB-coated IDA electrodes, a cyclic voltammogram was taken between 0.5 and $-0.2 \mathrm{~V}$ vs. $\mathrm{Ag} / \mathrm{AgCl}$ in $1 \mathrm{M} \mathrm{KCl}$ while the two-fingered electrodes were short-circuited; this was done for two reasons: from the integrated current-voltage curve the charge density and hence the average film thickness was determined, and the reduction of $\mathrm{PB}$ to Prussian White and subsequent reoxidation to PB changes the virginal state of the film to a reproducible state with a well defined structure [13]. This kind of electrochemical experiment was conducted in a conventional three-electrode cell with a $\mathrm{Pt}$ counter electrode and an $\mathrm{Ag} / \mathrm{AgCl}$ reference electrode by using a Jaissle potentiostat (Model 1001), a signal generator (Model DPG 72, Bank) and a precision potential-measuring device (Model PPT 75, Bank). Typical IDA electrode measurements (see Fig. 2) were made with a voltage, $\Delta E$, of $10-50 \mathrm{mV}$ applied between the two-fingered electrodes, meanwhile potentiostatically controlling the bias potential, $E_{\mathrm{b}}$, of the film with respect to a $\mathrm{Ag} /$ $\mathrm{AgCl}$ reference electrode. This electrode served at the same time as the counter electrode. The electronic equipment for this kind of measurement was either a bipotentiostat (Model Bipad, Tacussel) or a laboratory-made current amplifier with a sensitivity up to $10^{-12} \mathrm{~A}$. The measured data were stored and processed by a computer (Commodore Model 4032) via an AD converter. All experiments were performed at room temperature $\left(22 \pm 1^{\circ} \mathrm{C}\right)$.

\section{RESULTS AND DISCUSSION}

\section{General considerations}

In using a PB-coated IDA electrode as a chemiresistor, the following assumptions are made. First, the $\mathrm{PB}$ film is in thermodynamic equilibrium throughout while measuring the steady-state (diffusion) current, $i_{\mathrm{d}}$, i.e., at the electrode /PB film interphase an electronic equilibrium exists and at the PB film/electrolyte interphase an ionic equilibrium, the two equilibria being coupled.

Second, the reduction of the high-spin Fe redox centres within the film occurs reversibly and is accompanied by reversible insertion of cations from the electrolyte, without interaction of the latter with the host lattice. Therefore, the Nernst equation

$E=E^{\circ \prime}+(R T / F) \ln [x /(1-x)]\left(c / c^{\circ}\right)$

holds, corresponding to the reaction

$\mathrm{ox}_{\mathrm{f}}+\mathrm{e}^{-}+\mathrm{C}^{+} \rightleftharpoons \operatorname{red}_{\mathrm{f}}$
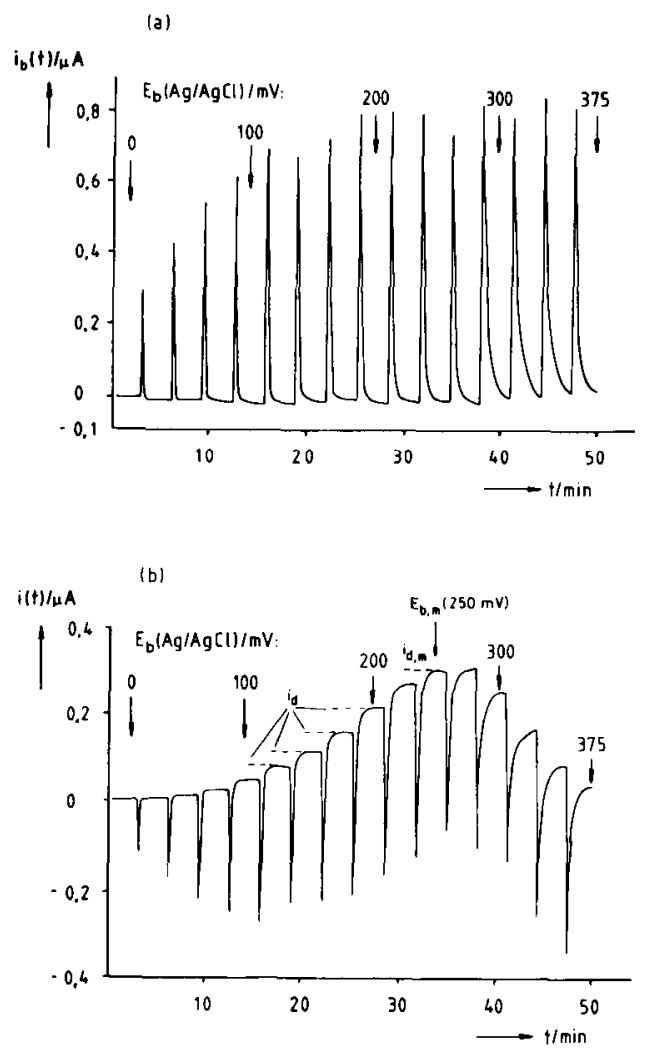

Fig. 3. (a) Bias current, $i_{\mathrm{b}}(t)$, and (b) current, $i(t)$, of a PB-coated IDA as a function of time. Numbers indicate the bias potential, $E_{\mathrm{b}}$, in $\mathrm{mV}$ vs. $\mathrm{Ag} / \mathrm{AgCl}$, stepped in $25-\mathrm{mV}$ increments and beginning at $0 \mathrm{~V}$ vs. $\mathrm{Ag} / \mathrm{AgCl}$. Electrolyte, 0.1 $\mathrm{M} \mathrm{RbCl} ; \Delta E=10 \mathrm{mV}$; gap between fingers, $3 \mu \mathrm{m}$. 


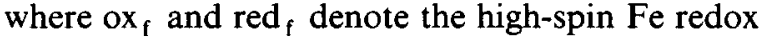
centres in the oxidized and reduced state, respectively, and $\mathrm{C}^{+}$denotes the cations in the electrolyte with concentration $c ; c^{\circ}$ is the standard concentration $\left(1 \mathrm{~mol} \mathrm{dm}^{-3}\right)$, and $x=c_{\mathrm{ox}} / c_{\mathrm{f}}$ is the mole fraction of oxidized redox centres with $c_{\mathrm{f}}=$ $c_{\mathrm{ox}}+c_{\text {red }}$ denoting the total concentration of the high-spin Fe redox centres. Hence the still controversal question of whether the structure of PB must be considered "soluble" $\left\{\mathrm{KFe}\left[\mathrm{Fe}(\mathrm{CN})_{6}\right]\right\}$ or "insoluble" $\left\{\mathrm{Fe}_{4}\left[\mathrm{Fe}(\mathrm{CN})_{6}\right]_{3} \cdot 6 \mathrm{H}_{2} \mathrm{O}\right\}$ or a mixture of both $[13,15]$ is ignored for the present.

Third, the geometric arrangement of the PBcoated IDA electrode (see Fig. 1b) is simplified by neglecting those portions of the film above the fingers.

For measurements with the PB-coated IDA electrode, the following experimental procedure is chosen. A small voltage $\Delta E$ is applied between the two-fingered electrodes (see Fig. 2) and, at any given reference concentration $c^{\prime}$, the maximum value of the steady-state current, $i_{\mathrm{d}, \mathrm{m}}$, at the average (bias) potential, $E_{\mathrm{b}, \mathrm{m}}$ (see Appendix), is measured. A typical registration curve for the determination of $i_{\mathrm{d}, \mathrm{m}}$ and $E_{\mathrm{b}, \mathrm{m}}$ is shown in Fig. $3 \mathrm{~b}$.

Thereafter the electrolyte of reference concentration, $c^{\prime}$, is replaced with the electrolyte of unknown concentration, $c$, resulting in a steadystate current, $i_{\mathrm{d}}$, which is related to $c$ by the following equation (see Appendix):

$i_{\mathrm{d}} / i_{\mathrm{d} . \mathrm{m}}=\left(4 c / c^{\prime}\right) /\left[1+\left(c / c^{\prime}\right)\right]^{2}$

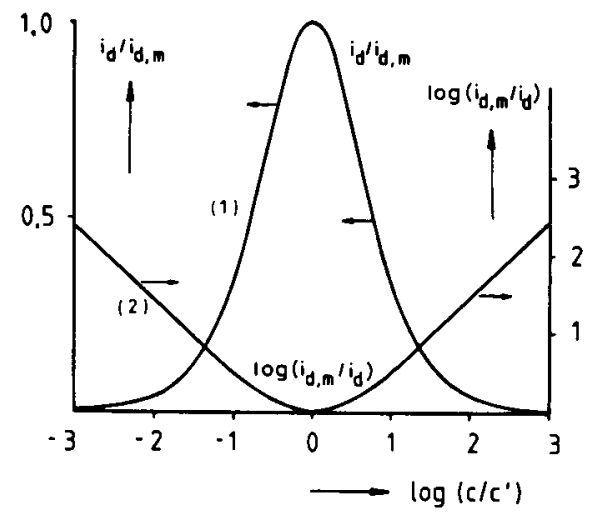

Fig. 4. Normalized steady-state current, $i_{\mathrm{d}} / i_{\mathrm{d} . \mathrm{m}}$ (curve 1), and $\log \left(i_{\mathrm{d}, \mathrm{m}} / i_{\mathrm{d}}\right)$ (curve 2 ) as a function of the logarithm of the normalized concentration $c / c^{\prime}$ according to Eqns. 3 and 4 .
This equation can be expressed by the approximated equation

$\log \left(i_{\mathrm{d}, \mathrm{m}} / i_{\mathrm{d}}\right) \approx-0.6 \pm \log \left(c / c^{\prime}\right)$

The relationships expressed by eqns. 3 and 4 are depicted in Fig. 4. Curve 1 is a bell-shaped curve corresponding to the usual current-voltage curve of an ideal insertion electrode [18]. Curve 2 shows that for $c<0.1 c^{\prime}$ and $c>10 c^{\prime}$ linear relationships between $i_{\mathrm{d}}$ and $1 / i_{\mathrm{d}}$, respectively, on the one hand and $c$ on the other are obtained:

$i_{\mathrm{d}} \approx\left(4 i_{\mathrm{d}, \mathrm{m}} / c^{\prime}\right) c$ and $1 / i_{\mathrm{d}} \approx\left(1 / 4 i_{\mathrm{d}, \mathrm{m}} c^{\prime}\right) c$

Time dependence of the current, $i(t)$, flowing between the fingered electrodes, and of the bias current, $i_{b}(t)$

Before making the above-mentioned measurements with the IDA electrodes, the time dependence of the current, $i(t)$, flowing between the fingered electrodes, and of the bias current, $i_{\mathrm{b}}(t)$, was studied at different bias potentials $E_{\mathrm{b}}$. A typical measurement is presented in Fig. 3, where $E_{\mathrm{b}}$ is stepped by increments of $25 \mathrm{mV}$ from 0 to $0.375 \mathrm{~V}$, i.e., from the reduced state of PB (Prussian White or Everitt's salt) to the oxidized state (PB). The bias current, $i_{\mathrm{b}}(t)$, represents that current which is consumed to bring the PB film to the new redox state at each step; it decays to zero within about 2-3 min depending on the respective bias potential. Within the same time interval, the current, $i(t)$, reaches a steady-state value, $i_{\mathrm{d}}$. It should be noted that the time elapsed before reaching the steady state depends on the width of the IDA gap. With the relatively small gap of width $3 \mu \mathrm{m}$, the steady-state current, $i_{\mathrm{d}}$, is obtained within 2-3 $\mathrm{min}$.

The potential stepping experiment depicted in Fig. 3 is completely analogous to the methods of "staircase coulometry" and "scanning conductivity" employed by Feldman and Murray [5] for the determination of the electron diffusion coefficient, $D_{\mathrm{e}}$. Thus, the latter can be determined from the relationship

$D_{\mathrm{e}}=i_{\mathrm{d}} d p N / Q(N-1)$ 
which was derived [4] from application of Fick's first law to the IDA electrode and relating the resulting steady-state current, $i_{\mathrm{d}}$, to the charge, $Q$, consumed by the PB film at each potential step and obtained from integrating the $i_{\mathrm{b}}(t)-t$ curve for one "pulse" (Fig. 3a). $p=w+d$ is the sum of the finger width, $w$, and gap width, $d$ and $N$ is the number of fingers. As shown in Fig. 5 for $\mathrm{RbCl}, D_{\mathrm{e}}$ depends on the bias potential and hence on the redox state of the film, with a maximum value at about $0.25 \mathrm{~V}$ vs. $\mathrm{Ag} / \mathrm{AgCl}$; the latter coincides approximately with the peak potential of a $\mathrm{RbCl}$ cyclic voltammogram which is about 0.275 $\mathrm{V}$ [15]. The variation in $D_{\mathrm{e}}$ with the composition of the film can be understood by considering the electronic motion as a hopping process from a reduced redox centre to an oxidized one; if the concentration of either species decreases, $D_{\mathrm{e}}$ decreases also, and $D_{\mathrm{e}}$ reaches a maximum value if the concentrations of the reduced and oxidized redox centres are identical.

A particular feature of Fig. 5 is the fact that the maxima of $i_{\mathrm{d}}$ and $Q$ do not coincide. This has been explained [5] by two electron conduction channels existing in PB, a slower one operative at higher potentials and being due to high-spin $\mathrm{Fe}$ coordinated asymmetrically by four isocyano groups and two $\mathrm{H}_{2} \mathrm{O}$ molecules, and a faster one operative at more negative potentials and being due to high-spin Fe coordinated symmetrically by six isocyano groups. Similar curves to those given

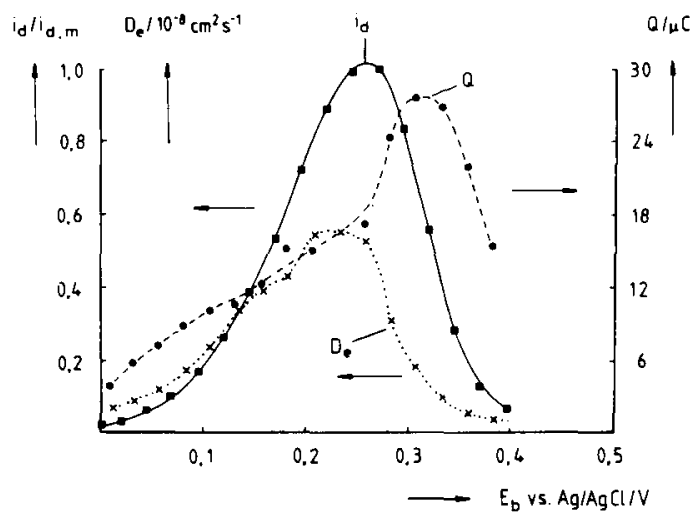

Fig. 5. Normalized steady-state current, $i_{\mathrm{d}} / i_{\mathrm{d} . \mathrm{m}}$, charge, $Q$, and electron diffusion coefficient, $D_{\mathrm{e}}$, as a function of the bias potential, $E_{\mathrm{b}}$. Electrolyte, $0.1 \mathrm{M} \mathrm{RbCl} ; \Delta E=10 \mathrm{mV}$; maximum steady-state current, $i_{\mathrm{d}, \mathrm{m}}=254 \mathrm{nA}$.

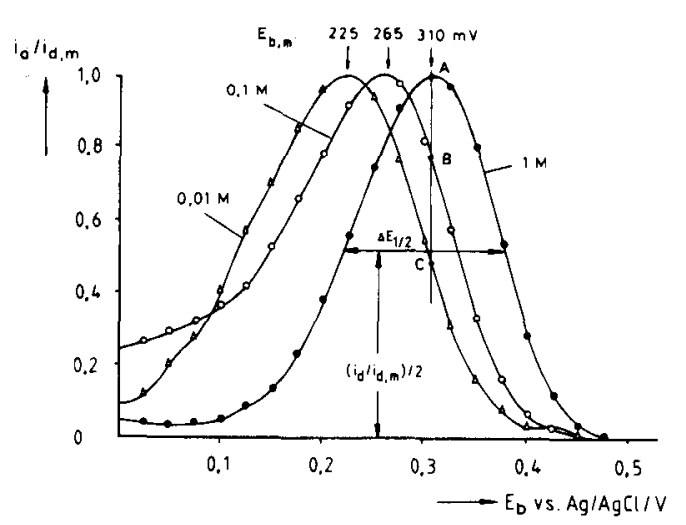

Fig. 6. Normalized steady-state current, $i_{\mathrm{d}} / i_{\mathrm{d}, \mathrm{m}}$, as a function of the bias potential, $E_{\mathrm{b}}$, at three different concentrations of RbCl. $\Delta E=50 \mathrm{mV} ; E_{\mathrm{b}, \mathrm{m}}=$ potential of maximum steady-state current, $i_{\mathrm{d}, \mathrm{m}} ; i_{\mathrm{d}, \mathrm{m}}=405 \mathrm{nA}(1 \mathrm{M}), 300 \mathrm{nA}(0.1 \mathrm{M}), 590 \mathrm{nA}$ $(0.01 \mathrm{M}) . \Delta E_{1 / 2}=$ width at half-height.

in Fig. 5 for $\mathrm{RbCl}$ are obtained for $0.1 \mathrm{M} \mathrm{KCl}$ and $0.1 \mathrm{M} \mathrm{CsCl}$. From these curves the maximum values for $D_{\mathrm{e}}$ which exceed the minimum values by a factor of ca. 10 , are determined to be $(7.4 \pm$ 2.3) $\times 10^{-9} \mathrm{~cm}^{2} \mathrm{~s}^{-1}$ for $\mathrm{K}^{+},(9.8 \pm 4.7) \times 10^{-9} \mathrm{~cm}^{2}$ $\mathrm{s}^{-1}$ for $\mathrm{Rb}^{+}$and $(11.5 \pm 6.2) \times 10^{-9} \mathrm{~cm}^{2} \mathrm{~s}^{-1}$ for $\mathrm{Cs}^{+}$. They compare satisfactorily with values given in [5]: $(3.9 \pm 1.3) \times 10^{-9},(6.6 \pm 2.0) \times 10^{-9}$ and $3.3 \times 10^{-9} \mathrm{~cm}^{2} \mathrm{~s}^{-1}$, respectively.

Dependence of the steady-state current, $i_{d}$, on the bias potential, $E_{b}$

The steady-state current, $i_{\mathrm{d}}$, measured as depicted in Fig. 3 and normalized with respect to $i_{\mathrm{d}, \mathrm{m}}$ is plotted against the bias potential, $E_{\mathrm{b}}$, in Fig. 6 for three different concentrations of $\mathrm{RbCl}$. For $c=1 \mathrm{M}$ a nearly ideal bell-shaped curve is obtained, in agreement with curve 1 in Fig. 4. However, the width at half-height, $\Delta E_{1 / 2}$, is much larger (about $160 \mathrm{mV}$ ) than the value of $90 \mathrm{mV}$ predicted by theoretical considerations on the basis of an ideal insertion electrode [18]. It is therefore concluded that the insertion of $\mathrm{Rb}^{+}$into $\mathrm{PB}$ occurs with some repulsive interaction with the host lattice, resulting in a broadened width at half-height $[18,19]$. A similar broadening of $\Delta E_{1 / 2}$ for $\mathrm{Rb}^{+}$is observed in cyclic voltammograms [13].

Figure 6 shows further that, for lower concentrations, the width at half-height becomes larger compared with the value at $1 \mathrm{M}: 236 \mathrm{mV}$ at $0.1 \mathrm{M}$ 
and $190 \mathrm{mV}$ at $0.01 \mathrm{M}$. The reason for this might be twofold: with decreasing concentration, the time for the diffusion current, $i(t)$, attaining the steady state, $i_{\mathrm{d}}$, becomes larger, so it may happen that the measured $i_{\mathrm{d}}$ is not the steady-state value but larger, resulting in a distortion of the $i_{\mathrm{d}}-E_{\mathrm{b}}$ curve; second, because with decreasing concentration the potential at the maximum steady-state current, $E_{\mathrm{b}, \mathrm{m}}$, shifts in a negative direction (see below), the disturbance of $i_{\mathrm{d}}$ measurements caused by parasitic reduction processes (e.g. by traces of oxygen) at negative potentials becomes more serious. This is seen in Fig. 6 for the curve at $0.1 \mathrm{M}$ $\mathrm{RbCl}$, where still considerable cathodic currents are observed below $0.1 \mathrm{~V}$.

When, for a given reference concentration, $c^{\prime}$ (e.g., $1 \mathrm{M}$ ), the bias potential is fixed potentiostatically at the potential, $E_{\mathrm{b}, \mathrm{m}}$, of maximum steadystate current, $i_{\mathrm{d}, \mathrm{m}}$, and subsequently the concentration is changed, the steady-state current also changes. This corresponds to a transition of point $A$ in Fig. 6 to points B and C, respectively. From such a type of measurement, the dependence of $i_{\mathrm{d}}$ on the concentration is obtained, as shown theoretically by curve 2 in Fig. 4, and experimentally in Fig. 7 for different values of $c^{\prime}$. Qualitatively, the two curves compare well, indicating a linear dependence of $i_{\mathrm{d}}$ on $c$ at $c<0.1 c^{\prime}$ and of $1 / i_{\mathrm{d}}$ at $c>10 c^{\prime}$ (see Eqn. 3a). However, the slope of the $\log \left(i_{\mathrm{d}, \mathrm{m}}^{\prime} / i_{\mathrm{d}}\right)-\log \left(c / c^{\prime}\right)$ curve obtained experimentally $(-0.33)$ is smaller than the theoretical value $(-1)$ by a factor of 3 . This follows immediately from the fact that the $\Delta E_{1 / 2}$ value increases with decreasing concentration, leading to $i_{\mathrm{d}}$ values

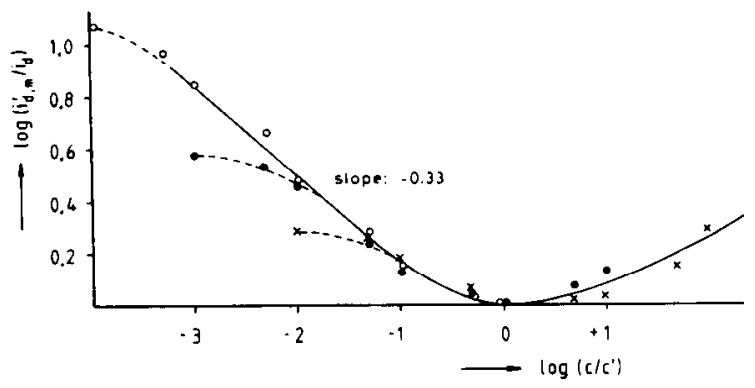

Fig. 7. Logarithmic plot of the inverse normalized steady-state current, $i_{\mathrm{d}, \mathrm{m}} / i_{\mathrm{d}}$, versus the normalized concentration, $c / c^{\prime}$. Electrolyte, RbCl. Reference concentration, $c^{\prime}=(0) 1,(\bullet) 0.1$ and (x) $0.01 \mathrm{M} ; E_{\mathrm{b}, \mathrm{m}}=(0) 310$, (•) 265 and (x) $225 \mathrm{mV}$.

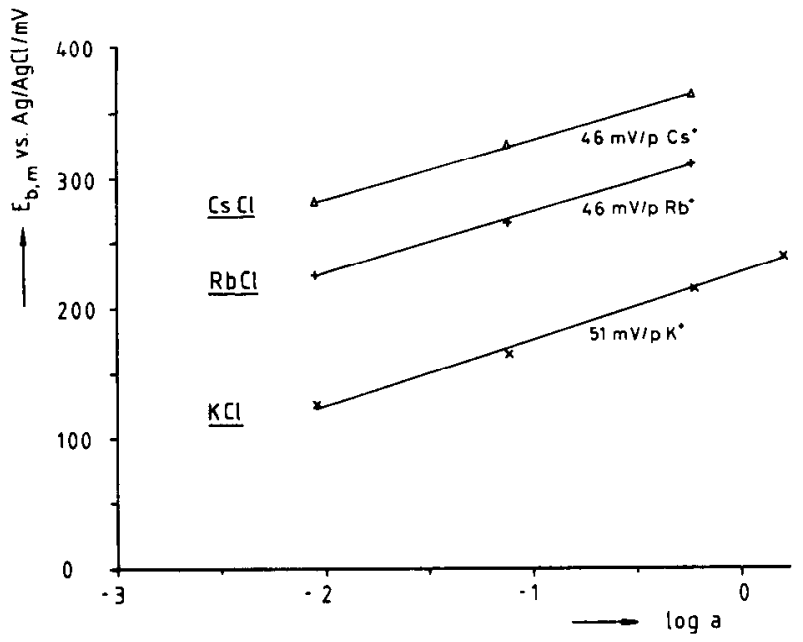

Fig. 8. Bias potential of maximum steady-state current, $E_{\mathrm{b}, \mathrm{m}}$, as a function of the cation activity, a. Electrolyte: $\mathrm{KCl}, \mathrm{RbCl}$ and $\mathrm{CsCl}$. Numbers indicate the slopes of the straight lines.

larger than expected for an ideal $\Delta E_{1 / 2}$ of $90 \mathrm{mV}$. Larger $i_{\mathrm{d}}$ values, however, cause a smaller slope (see Fig. 7).

In addition, Fig. 7 shows deviations from linearity of the $\log \left(i_{\mathrm{d}, \mathrm{m}}^{\prime} / i_{\mathrm{d}}\right)-\log \left(c / c^{\prime}\right)$ plot for small proportions $c / c^{\prime}$, these deviations being greater the smaller $c^{\prime}$ is. Thus, for $c^{\prime}=1 \mathrm{M}$ the deviation from linearity occurs at $c / c^{\prime}<10^{-3}$, but for $c=$ $10^{-2} \mathrm{M}$ this deviation is observed at $c / c^{\prime}=10^{-2}$.

An explanation of this behaviour can be given on the basis of the above-mentioned fact that the deviation of the $i_{\mathrm{d}}-E_{\mathrm{b}}$ curves from ideality (see Fig. 6) are the more pronounced the lower the concentration is, which leads to the $i_{\mathrm{d}}$ values becoming larger than expected for ideal behaviour.

Figure 6 reveals, in addition, that the potential of maximum steady-state current, $E_{\mathrm{b}, \mathrm{m}}$, depends on the concentration in a nearly Nernstian way, as predicted by Eqn. 1. This is shown in Fig. 8, which additionally contains results obtained with $\mathrm{KCl}$ and $\mathrm{CsCl}$. The $i_{\mathrm{d}}-E_{\mathrm{b}}$ curves, from which the straight lines in Fig. 8 were derived for different concentrations of $\mathrm{KCl}$ and $\mathrm{CsCl}$, are similar to those for $\mathrm{RbCl}$ presented in Fig. 6. Only the $E_{\mathrm{b}, \mathrm{m}}$ values are shifted either to more positive potentials $(\mathrm{CsCl})$ or to more negative potentials $(\mathrm{KCl})$. Thus, at a concentration of $0.1 \mathrm{M}, E_{\mathrm{b}, \mathrm{m}}$ is $165 \mathrm{mV}$ 
for $\mathrm{K}^{+}, 265 \mathrm{mV}$ for $\mathrm{Rb}^{+}$and $325 \mathrm{mV}$ for $\mathrm{Cs}^{+}$(all values vs. $\mathrm{Ag} / \mathrm{AgCl}$ ).

The fact that the straight lines in Fig. 8 exhibit slopes smaller than the Nernstian value of $59 \mathrm{mV}$ per activity decade is similar to findings obtained with a copper hexacyanoferrate(II)-modified glassy carbon electrode applied to the determination of $\mathrm{K}^{+}$and $\mathrm{NH}_{4}^{+}$[20]. It can be explained by assuming that the $\mathrm{PB}$ layer is not ideally permselective, rather than that a certain amount of co-ions $\left(\mathrm{Cl}^{-}\right)$ can enter the film. Indications for this behaviour have been obtained recently from Donnan potential measurements on PB membranes prepared by chemical deposition of PB on perforated foils [21].

\section{Selectivity measurements}

The selectivity of a PB-coated IDA electrode with respect to different alkali metal ions was studied by taking $i_{\mathrm{d}} / i_{\mathrm{d}, \mathrm{m}}-E_{\mathrm{b}}$ curves (see Fig. 6) for mixtures of alkali metal ions with variable concentration. Figure 9 shows typical curves obtained with an aqueous solution of $0.5 \mathrm{M} \mathrm{LiCl}$ containing different concentrations of $\mathrm{CsCl}$ and resulting in the curves a-d. The potential, $E_{\mathrm{b}, \mathrm{m}}$, of maximum steady-state current depends on the $\mathrm{Cs}^{+}$ concentration in a nearly Nernstian fashion, as demonstrated in Fig. 10 (line b). Only the slope of the $E_{\mathrm{b}, \mathrm{m}}-\log a\left(\mathrm{Cs}^{+}\right)$straight line is depressed

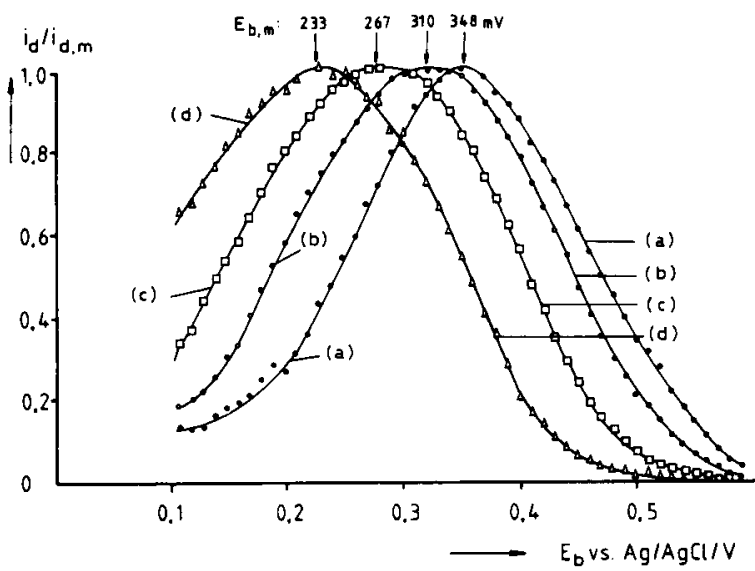

Fig. 9. Normalized steady-state current, $i_{\mathrm{d}} / i_{\mathrm{d} . \mathrm{m}}$, as a function of the bias potential, $E_{\mathrm{b}}$, for $0.5 \mathrm{M} \mathrm{LiCl}$ containing different concentrations of $\mathrm{CsCl}$ : (a) 0.5 , (b) $5 \times 10^{-2}$, (c) $5 \times 10^{-3}$ and (d) $5 \times 10^{-4}$ M. $\Delta E=25 \mathrm{mV} ; i_{\mathrm{d}, \mathrm{m}}=$ (a) 285 , (b) 510 , (c) 630 and (d) $230 \mathrm{nA}$.

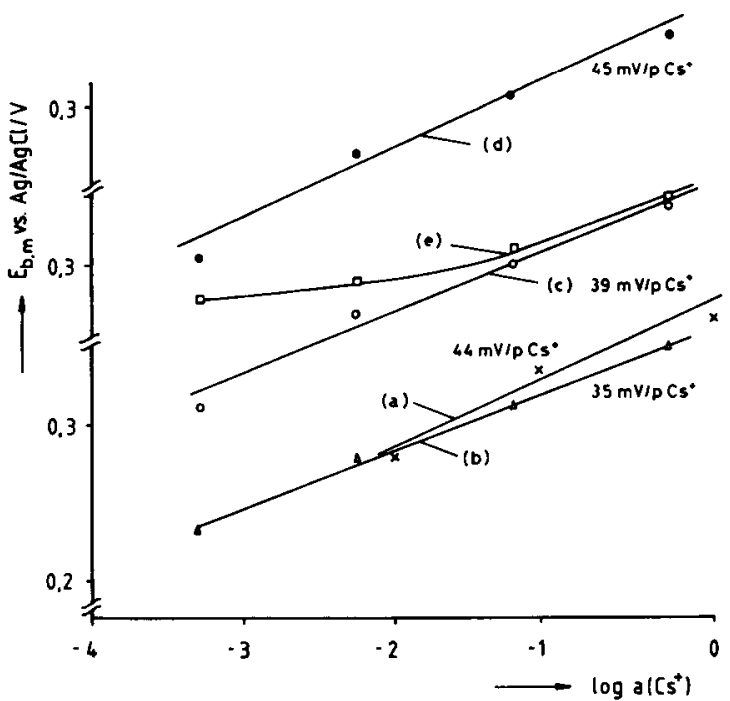

Fig. 10. Bias potential of maximum steady-state current, $E_{\mathrm{b}, \mathrm{m}}$, as a function of the activity of $\mathrm{Cs}^{+}$in $0.5 \mathrm{M}$ solutions of (b) $\mathrm{LiCl}$, (c) $\mathrm{NaCl}$, (d) $\mathrm{KCl}$ and (e) $\mathrm{RbCl}$. Line a was obtained from pure $\mathrm{CsCl}$ solutions. Numbers indicate slopes. (The curves are shifted on the potential axis for clarity.)

compared with $\mathrm{Li}^{+}$-free $\mathrm{CsCl}$ solutions (Fig. 10, line a). The straight lines in Fig. 10 demonstrate that, except for $\mathrm{Rb}^{+}$(line e), the linear dependence of $E_{\mathrm{b}, \mathrm{m}}$ on $\log a\left(\mathrm{Cs}^{+}\right)$is not altered in the presence of $0.5 \mathrm{M}$ solutions of $\mathrm{Li}^{+}, \mathrm{Na}^{+}$or $\mathrm{K}^{+}$ ions. Hence the PB-coated IDA electrode is highly selective for $\mathrm{Cs}^{+}$against $\mathrm{Li}^{+}, \mathrm{Na}^{+}$and $\mathrm{K}^{+}$ions with selectivity coefficients [22] smaller than ca. $10^{-3}$. The selectivity for $\mathrm{Cs}^{+}$with respect to $\mathrm{Rb}^{+}$ is lower, as revealed by the non-linear course of line e. From the latter, an approximate selectivity coefficient of $K_{\mathrm{CsRb}} \approx 10^{-2}$ can be estimated.

\section{Conclusions}

It has been demonstrated that PB-coated IDA electrodes can be considered to be chemiresistors, the conductivity of which depends on the concentration of alkali metal ions in an adjacent electrolyte. Hence, such systems, in principle, can be used as alkali metal ion sensors. Their response, at constant bias potential, with respect to a change in cation concentration agrees qualitatively with predictions obtained from theoretical considerations. Deviations from theory can be traced back to deviations from ideal insertion 
behaviour being manifested by a broadening of the width at half-height of the steady-state current-bias potential curves. In addition, parasitic cathodic currents at low concentrations and at relatively negative bias potentials may cause a distortion of the $i_{\mathrm{d}}-c$ characteristics. Thus, for the non-optimized PB-coated IDA electrodes, an approximate detection limit of about $10^{-4} \mathrm{M}$ can be assumed.

An interesting feature of the PB chemiresistors is their selectivity, expressed by selectivity coefficients which, e.g., for $\mathrm{Cs}^{+}$, are smaller than $10^{-3}$ (except $K_{\mathrm{CsRb}} \approx 10^{-2}$ ). Similar selectivity behaviour exists for other alkali metal ions in the series $\mathrm{Cs}>\mathrm{Rb}>\mathrm{K}>\mathrm{Na}>\mathrm{Li}$. The advantage of this kind of alkali metal ion sensor, once microlithographically fabricated IDAs are available, is the ease of preparation, allowing the renewal of the active layer many times. In addition, the signal measured is a current, which may be advantageous for electronic circuitry. Finally, optimization of the measuring technique would probably lead to a lowering of the detection limit.

The authors are indebted to the Deutsche Forschungsgemeinschaft for financial support and to Johan Bomer for preparing the IDA electrodes.

\section{APPENDIX}

\section{Derivation of eqn. 3}

Considering the geometric arrangement of a PB-coated IDA electrode (see Fig. 1b) with neglect of those portions of the PB film which are located on top of the fingers, the application of a small voltage $\Delta E$ between the two-fingered electrodes causes the oxidation of $\mathrm{PB}$ at the positive pole and a corresponding reduction at the negative pole. Thus the mole fraction of oxidized redox centres adjacent to the two poles deviates from the original value $x$ by the increments $\delta x$, which can be derived from eqn. 1 by differentiation with respect to $x$ :

$$
\delta x=(F / R T) x(1-x) \delta E
$$

where $\delta E$ is half of the voltage $\Delta E$ applied to the two-fingered electrodes, $\Delta E=2 \delta E$. From the change in the mole fraction from the value $x$ to $x+\delta x$ at the positive pole and to $x-\delta x$ at the negative pole, a concentration gradient of the redox centres across the gap is established, leading to a steady-state diffusion current, $i_{\mathrm{d}}$ :

$i_{\mathrm{d}}=F A D_{\mathrm{e}} c_{\mathrm{f}} \Delta x / d$

where $\Delta x=2 \delta, A=(N-1) l h$ is the area of the electrode exposed to the film, neglecting the portion of the film on top of the fingers $(l=$ length and $h=$ height of a finger), $D_{\mathrm{e}}$ is the electron diffusion coefficient and $N$ is the number of fingers. Combination of eqns. 6 and 7 gives

$i_{\mathrm{d}}=\left(F^{2} / R T\right) A D_{\mathrm{e}} c_{\mathrm{f}} x(1-x) \Delta E / d$

describing the relationship between $i_{\mathrm{d}}$ and $x$ at fixed potential $E_{\mathrm{b}} \cdot E_{\mathrm{b}}$ is the bias potential, i.e., the average potential of the two-fingered electrodes, related to a reference electrode; thus, for the potential of the positive pole $E_{+}=E_{\mathrm{b}}+\Delta E / 2$ and for that of the negative pole $E_{-}=E_{\mathrm{b}}-\Delta E / 2$ holds (see Fig. 2).

As $x$ depends on $E_{\mathrm{b}}$ according to eqn. (1), the complete relationship between $i_{\mathrm{d}}, E_{\mathrm{b}}$ and $c$ is

$$
\begin{aligned}
i_{\mathrm{d}}= & \left(F^{2} A D_{\mathrm{e}} c_{\mathrm{f}} \Delta E / R T d\right) \\
& \times \frac{\left(c^{\circ} / c\right) \exp \left[F\left(E_{\mathrm{b}}-E^{\circ \prime}\right) / R T\right]}{\left\{1+\left(c^{\circ} / c\right) \exp \left[F\left(E_{\mathrm{b}}-E^{\circ \prime}\right) / R T\right]\right\}^{2}}
\end{aligned}
$$

Equation 9 parallels the known current function of a thin-layer cell or of an electroactive adsorbate [17]. For the particular case of $c=c^{\circ}$, Eqn. 9 predicts a maximum value of the steady-state current, $i_{\mathrm{d}, \mathrm{m}}$, at $E_{\mathrm{b}, \mathrm{m}}=E^{\circ}$ :

$i_{\mathrm{d}, \mathrm{m}}=F^{2} A D_{\mathrm{e}} c_{\mathrm{f}} \Delta E /(4 R T d)$

As can be seen from Eqn. 1, this situation is characterized by the fact that $x=1 / 2$, i.e., the concentration of the oxidized redox centres is equal to that of the reduced ones; it corresponds to the peak current and the peak potential of a cyclic voltammogram. Equation 1 shows further that this situation $(x=1 / 2)$ prevails also at concentrations others than $c=c^{\circ}$, whereby the potential, $E_{\mathrm{b}, \mathrm{m}}$, of the current maximum, $i_{\mathrm{d}, \mathrm{m}}$, shifts in negative di- 
rection by $59 \mathrm{mV}$ on a concentration change of one decade:

$E_{\mathrm{b}, \mathrm{m}}=E^{\circ \prime}+(R T / F) \ln \left(c / c^{\circ}\right)$

Hence, defining any reference concentration, $c^{\prime}$, for which $E_{\mathrm{b}, \mathrm{m}}$ and $i_{\mathrm{d}, \mathrm{m}}$ were determined experimentally, the following relationship is obtained by combining Eqns. 9, 10 and 11:

$i_{\mathrm{d}} / i_{\mathrm{d}, \mathrm{m}}=\left(4 c / c^{\prime}\right) /\left[1+\left(c / c^{\prime}\right)\right]^{2}$

which holds for a fixed bias potential at $E_{\mathrm{b}, \mathrm{m}}$ and for the electrolyte of reference concentration $c^{\prime}$ being replaced with an electrolyte of concentration $c$.

\section{REFERENCES}

1 H.S. White, G.P. Kittlesen and M.S. Wrighton, J. Am. Chem. Soc., 106 (1984) 5375.

2 M.S. Wrighton, Comments Inorg. Chem., 4 (1985) 269.

3 C.E. Chidsey, B.J. Feldman, C.A. Lundgren and R.W. Murray, Anal. Chem., 58 (1986) 601.

4 B.J. Feldman and R.W. Murray, Anal. Chem., 58 (1986) 2844.

5 B.J. Feldman and R.W. Murray, Inorg. Chem., 26 (1987) 1702.

6 V.D. Neff, J. Electrochem. Soc., 125 (1978) 886.

7 K. Itaya, T. Ataka and S. Toshima, J. Am. Chem. Soc., 104 (1982) 3751.
8 K. Itaya, N. Shoji and J. Uchida, J. Am. Chem. Soc., 106 (1984) 3423.

9 D. Ellis, M. Eckhoff and V.D. Neff, J. Phys. Chem., 85 (1981) 1225; K. Itaya, K. Shibayama, H. Akahoshi and S. Toshima, J. Appl. Phys., 53 (1982) 804.

10 V.D. Neff, J. Electrochem. Soc., 132 (1985) 1382.

11 E.W. Grabner and S. Kalwellis-Mohn, J. Appl. Electrochem., 17 (1987) 653.

12 P.J. Kulesza and K. Doblhofer, J. Electroanal. Chem., 274 (1989) 95.

13 C.A. I.undgren and R.W. Murray, Inorg. Chem., 27 (1988) 933.

14 K. Itaya, J. Uchida and V.D. Neff, Acc. Chem. Res., 19 (1986) 162, and references cited therein.

15 J.W. McCargar and V.D. Neff, J. Phys. Chem., 92 (1988) 3598.

16 H. Albers, in J.C. Lodder (Fd.), Sensors and Actuators, Microtechnology for Transducers, Kluwer, Deventer, 1986.

17 A.J. Bard and L.R. Faulkner, Electrochemical Methods, Wiley, New York, 1980, pp. 410, 522

18 W.R. McKinnon and R.R. Haering, in J.O'M. Bockris and A. Conway (Eds.), Modern Aspects of Electrochemistry, Vol. 15, Plenum, New York, 1983, p. 235.

19 D. Engel and E.W. Grabner, Z. Phys. Chem., N.F., 160 (1988) 151.

20 D. Engel and E.W. Grabner, Ber. Bunsenges. Phys. Chem., 89 (1985) 982.

21 H. Fuchs, Diplomarbeit, University of Frankfurt, 1990.

22 G.J. Moody and J.D.R. Thomas, Selective Ion Sensitive Electrodes, Merrow, Watford, 1971, p. 14. 